\title{
Minimally invasive techniques for epilepsy surgery: stereotactic radiosurgery and other technologies
}

\author{
A review \\ Mark Quigg, M.D., M.Sc., ${ }^{1}$ And Cynthia Harden, M.D. ${ }^{2}$ \\ ${ }^{1}$ Department of Neurology, University of Virginia Heath System, Charlottesville, Virginia; and ${ }^{2}$ Department of \\ Neurology, Hofstra University, Hempsted, New York
}

\begin{abstract}
Minimally invasive surgical techniques for the treatment of medically intractable epilepsy, which have been developed by neurosurgeons and epileptologists almost simultaneously with standard open epilepsy surgery, provide benefits in the traditional realms of safety and efficacy and the more recently appreciated realms of patient acceptance and costs. In this review, the authors discuss the shortcomings of the gold standard of open epilepsy surgery and summarize the techniques developed to provide minimally invasive alternatives. These minimally invasive techniques include stereotactic radiosurgery using the Gamma Knife, stereotactic radiofrequency thermocoagulation, laser-induced thermal therapy, and MRI-guided focused ultrasound ablation.
\end{abstract} (http://thejns.org/doi/abs/10.3171/2014.8.GKS141608)

KEY WORDS $\bullet \quad$ epilepsy surgery $\bullet \quad$ stereotactic radiosurgery $\bullet \quad$ laser ablation $\bullet$
thermocoagulation $\bullet \quad$ focused ultrasound $\bullet \quad$ mesial temporal lobe epilepsy

$\mathrm{T}$ HE lesions encountered in epilepsy surgery are often physiologically defined rather than discrete structural lesions; therefore, physicians involved with the evaluation leading up to and performance of epilepsy surgery are always pushing technology to determine what minimal extent of a surgical lesion can interrupt the critical circuits that define an epileptic network, what techniques can minimize invasive procedures required in defining these epileptic networks, and what surgical techniques can perform modification to or ablation of the target with the least morbidity and invasion. This review outlines the ongoing development of techniques of minimally invasive epilepsy surgery, including stereotactic radiosurgery (SRS), stereotactic radiofrequency thermocoagulation (SRT), laser-induced thermal therapy (LITT), and MRI-guided focused ultrasound ablation (FUS).

\footnotetext{
Abbreviations used in this paper: $\mathrm{ATL}=$ anterior temporal lobectomy; AVM = arteriovenous malformation; $\mathrm{CM}=$ cavernous malformation; FUS = focused ultrasound ablation; $\mathrm{HH}=$ hypothalamic hamartoma; LITT = laser-induced thermal therapy; MTLE = mesial temporal lobe epilepsy; SEEG = stereo-electroencephalography; $\mathrm{SRS}=$ stereotactic radiosurgery; $\mathrm{SRT}=$ stereotactic radiofrequency thermocoagulation; SUDEP = sudden unexpected death in epilepsy.
}

\section{Open Surgery}

Before discussion of minimally invasive techniques, a brief rationale for looking past open surgery is necessary. After all, craniotomy and anterior temporal lobectomy (ATL) are the gold standards established by Wiebe et al. in their randomized controlled trial of surgery versus "best medical therapy" for mesial temporal lobe epilepsy (MTLE). ${ }^{79}$ This study showed that whereas only $8 \%$ of patients achieved seizure freedom for a year's durationwith 1 death-almost $60 \%$ achieved seizure freedom after ATL with no clear surgical morbidities (beyond expected visual field cuts after ATL). ${ }^{28}$

A reasonable question is, "Why should SRS be used when standard techniques may be good enough?"

One answer is utilization. ATL remains underutilized because of perceived risk, cost, and lack of willingness to seek specialized centers. ${ }^{6,40}$ Despite clear standards guiding physicians in the consideration of epilepsy surgery ${ }^{19}$ and despite the proliferation of epilepsy centers, the actual number of surgeries has stayed flat. ${ }^{20}$ Patients and referring physicians may be reluctant to invoke invasive surgery, leading to delays of definitive treatment.

Medical care costs, especially for open surgery re- 
quiring intensive care, are considerable. For example, the average cost per patient for treatment of arteriovenous malformations (AVMs) with open microsurgery is nearly $50 \%$ more than that with minimally invasive SRS. ${ }^{78}$

Primary morbidities of open surgery are admittedly low but remain significant because epilepsy surgery is often considered an elective procedure; surgical risks include a $0.24 \%$ chance of death, a $2 \%$ chance of serious permanent complications, and a $6 \%$ chance of transient complications. ${ }^{73}$ Secondary morbidities, especially in neurocognition, also remain significant. For example, impairments of verbal learning and memory have been demonstrated in $10 \%-60 \%$ of patients who undergo open ATL on the dominant hemisphere, ${ }^{10,29,30,71}$ whereas less consistent declines in visual memory are associated with ATL on the nondominant hemisphere.$^{47}$ In a multicenter prospective epilepsy surgery trial, an overall $38 \%$ prevalence of verbal memory decline after ATL was documented, with the greatest predictor being side of surgery. ${ }^{71}$ Of dominant-hemisphere surgery patients in this series, $40 \%$ declined in 1 measure of verbal memory and another $20 \%$ declined in 2 measures, for an overall prevalence of $60 \% .^{71}$

Therefore, underutilization of surgery, attributable to patient and physician reluctance, high costs, and perceived as well as measurable morbidities, drives the search for minimally invasive alternatives to open epilepsy surgery.

\section{Stereotactic Radiosurgery}

SRS, either with the Gamma Knife (Elekta AB) or with various linear accelerators (Novalis Tx, Varian Medical Systems) and CyberKnife (Accuray, Inc.) deliver ionizing radiation to a focal target. The Gamma Knife consists of about 200 separate radioactive cobalt-60 sources housed inside a hemispheric chamber and focused to a single target. The target, in turn, is determined and maintained with the patient positioned in a stereotactic frame. The linear accelerators move to deliver beams about various vectors to construct a focus point within the calculated center. Unless noted, most work cited below involves the Gamma Knife.

Of the techniques discussed in this review, SRS has the widest and deepest range of publications reflecting clinical experience and basic science investigations over the last 60 years. Only recently, however, has SRS been specifically studied for its anticonvulsant effects.

\section{Lesional Epilepsies}

The anticonvulsant effects of SRS were first noted in treatments of mass lesions: tumors, AVMs, cavernous malformations (CMs), and hypothalamic hamartomas (HHs).

Tumors. Given the variety of CNS tumors, studies of SRS for treatment of tumor-associated epilepsy (as opposed to numerous reports on the efficacy of this technique for use on tumors themselves) are few. Schröttner et al., however, concentrated on the dose absorbed by tissue in tumor penumbra, dividing patients into 2 groups according to the volume of tissue outside the tumor that had received 10 Gy or more. ${ }^{62}$ Outcome was retrospectively ranked at a mean duration of about 2 years into "excellent" (Engel Class I-II) or not. Patients in the high-volume group achieved a 66\% improvement rate compared with $42 \%$ for those in the low-volume group. Because all patients achieved tumor control with SRS (thus removing tumor response as a confounder), the differing rates of seizure improvement suggest that higher SRS volumes delivered to tumor penumbra are important in treating tumor-associated epilepsy.

Arteriovenous Malformations. The anticonvulsant efficacy of SRS is most evident in the treatment of AVMs, with an across-study mean seizure remission rate of $70 \%{ }^{25,27,38,61,70}$ Representative is the large series accumulated by Steiner et al., who reported that seizures cease after SRS in $69 \%$ of patients with an AVM and epilepsy. ${ }^{70}$ A recent update from the same center reported that $89 \%$ of patients achieved seizure remission (measured as Engel Class Ia/b outcomes), and $33 \%$ of patients were tapered off of pre-SRS anticonvulsant medications.$^{53}$ Obliteration of the AVM nidus is not a consistent marker for seizure remission among the above studies. The most recent found that there was some contribution of obliteration of the nidus to the ability to discontinue anticonvulsant medications; of the patients who experienced complete seizure remission, $54 \%$ with patent nidi remained on anticonvulsants compared with $19 \%$ with complete AVM obliteration. ${ }^{53}$

Cavernous Malformations. The enthusiasm for the use of SRS for CMs remains mixed. The across-study proportion of seizure remission reported in retrospective case series is 50\%. ${ }^{4}$ Representing the extremes in efficacy, Shih and $\mathrm{Pan}^{66}$ reported mean margin doses of 13 Gy and central doses of 21 Gy for a remission rate of $25 \%$, whereas Kim et al. ${ }^{36}$ used a mean margin dose of $15 \mathrm{~Gy}$ and a central dose of $26 \mathrm{~Gy}$ for a remission rate of $70 \%$. Retrospective studies of open resection suggest that removal of the hemosiderin-stained tissue surrounding the $\mathrm{CM}$ is associated with better outcome; ${ }^{5}$ therefore, variable outcomes following SRS may also stem from inconsistent inclusion of this potentially epileptogenic region in the treatment volume. With higher doses, however, radiation toxicity emerges as a concern. ${ }^{34}$ In a recent retrospective comparison, the authors concluded that open resection resulted in better seizure control and hemorrhage avoidance than SRS.66 This study, as well as comparisons to the approximately $70 \%-80 \%$ seizure remission rate seen after open surgery for $\mathrm{CM},{ }^{8,13}$ suggest that any benefits of noninvasive SRS over open surgery for CM must be weighed against risks of less efficacy and possibly increased toxicities.

Hypothalamic Hamartomas. These lesions frequently cause medically intractable gelastic and other seizures that are usually accompanied by behavioral and cognitive decline. SRS has an advantage of noninvasive access. Series of SRS treatment of $\mathrm{HH}^{1,44,56,60,64,75}$ demonstrate a seizure remission rate of $27 \%$ across studies. Although this rate appears low, seizure remission alone underestimates the benefits seen with respect to improved behavior and 
the need for less custodial care required in these cases of severe epilepsy. A European multicenter, prospective trial of SRS for HH enrolled 60 patients, 27 of whom exceeded 3 years of follow-up. ${ }^{60}$ Morbidity was low, with no ill effects except for one instance of poikilothermia noted among the above reports. Some reports emphasize the importance of the margin dose of radiation, ${ }^{60}$ as noted for tumors and AVMs. Patients treated with doses exceeding $17 \mathrm{~Gy}$ to the margin of the $\mathrm{HH}$ had greater rates of seizure remission than those receiving less than $13 \mathrm{~Gy} .{ }^{56}$

\section{Physiological Epilepsies}

Mesial Temporal Lobe Epilepsy. Extensive study has centered on focal epilepsies not caused by a discrete mass. MTLE consists of atrophy, gliosis, and selective neuronal loss within the hippocampus and associated limbic system. Régis et al. were the first to systematically evaluate SRS for treatment of MTLE in $1995,{ }^{58}$ and they then conducted a subsequent trial of 7 MTLE patients. ${ }^{57}$ In this series, a target comprising the parahippocampal gyrus, head and anterior body of the hippocampus, and amygdala, with an approximately $6.5-\mathrm{ml} 50 \%$ isodose volume, was treated with $25 \mathrm{~Gy}$. Since this publication, 9 studies treating a total of 83 patients have been reported. These studies demonstrate a wide range of efficacies of seizure remission, ranging from $0 \%$ to $86 \%, 2,12,31,35,46,52,57,59,68$ with an across-study average of $51 \%$. In comparison, the rate of seizure remission in the prospective, randomized trial of open surgery for MTLE was 58\%.79

The wide range of outcomes in seizure remission arose from the developing understanding of the anticonvulsant mechanism of ionizing radiation, dose/volume considerations, and patient selection.

Hypotheses on mechanisms of the anticonvulsant effect of ionizing radiation have centered on neuromodulation versus ablation. ${ }^{55}$ Animal models of focal epilepsy suggested that nondestructive neuromodulation was sufficient for seizure reduction. ${ }^{11,41}$ Single-center case series of SRS with "low-dose protocols" (dose < 24 Gy) informed by this work showed poor results..$^{12,31,35,52,68}$ In contrast, 2 larger, prospective multicenter studies, 1 European $^{59}$ and 1 American, ${ }^{2}$ used doses at or above $24 \mathrm{~Gy}$. The European trial demonstrated a 2-year postoperative seizure remission rate of $62 \%$ with the use of a treatment protocol identical to that used in the group's earlier studies. Barbaro et al., in the US Multicenter Pilot Study, ${ }^{2}$ randomized 30 patients to a high (24 Gy, $n=13$ ) or low (20 Gy, $n=17)$ dose delivered to the target as specified by Régis et al., 59 with the added specification that $50 \%$ isodose volumes were restricted to $5.5-7.0 \mathrm{ml}$. Ten patients in each group were seizure free at 36 months of follow-up, resulting in a remission rate of $77 \%$ in the high-dose and $59 \%$ in the low-dose group, for an overall remission rate of $67 \%$. Patients in the high-dose group had higher volumes of radiation-induced changes and had spectrographic evidence of necrosis in the target center, suggesting that higher doses caused ablations of the epileptic target. ${ }^{9}$

Patient selection is an important consideration in evaluating SRS treatment protocols. In fact, any minimally invasive surgical technique requires rigorous defi- nition of the target. SRS is, in effect, a "superselective" amygdalohippocampectomy involving the destruction of the minimum volume and anatomy important in the pathophysiology of MTLE. Patients with epilepsies that may differ from the stereotypic unilateral MTLE lesion may not be suitable for SRS. For example, most patients in a long-term cohort in whom SRS failed also had evidence for extension of the "epileptic zone" beyond mesial structures. ${ }^{3}$ In another trial with poor SRS results, one explanation for poor rates of seizure remission was that the primary epileptic injury in some patients could be considered symptomatic "MTLE plus." " Patients with evidence of involvement outside of the SRS target or with symptomatic etiologies may not experience seizure remission with the highly selective/minimally invasive techniques. Of course, this limitation is not unique to SRS.

Morbidities in the multicenter SRS protocols do not exceed those of open surgery and fall in line with those seen commonly after SRS. Superior quadrant field defects are an expected morbidity after standard temporal lobectomy, with rates of visual field defects between 52\% and $100 \% .{ }^{28}$ Quantified visual fields were measured in the US Multicenter Study at 24 months after SRS, with the finding that $62.5 \%$ of patients had postoperative visual field changes, all homonymous superior quadrantanopsias. ${ }^{28}$ Other morbidities consisted of headache, nausea, vomiting, and depression. Headache requires special comment as it coincides in some subjects with postoperative edema. Steroids, either in response to headache, visual field changes, or MRI changes, were used in $62 \%$ of patients. ${ }^{2}$

In the treatment of MTLE, one potential benefit of SRS - or indeed, of any minimally invasive surgery-is the sparing of neurocognitive function owing to the "superselectivity" of the minimally invasive lesion. The European prospective trial reported no mean neurocognitive changes through a 2-year follow-up period..$^{59}$ Detailed evaluation of neurocognitive outcomes was provided from the US Multicenter Trial. ${ }^{54}$ Mean scores of tests of language and verbal memory at 24 and 36 months after SRS did not differ from preoperative baselines. Specifically, significant verbal memory impairment was seen in $25 \%$ of dominant-hemisphere surgery patients and in $7 \%$ of nondominant-hemisphere surgery patients. In fact, significant improvement was seen in $16 \%$ of dominanthemisphere surgery and $7 \%$ of nondominant-hemisphere surgery patients. In comparison, rates of significant impairment following dominant-hemisphere temporal lobectomy range from $10 \%$ to $60 \% .^{10,29,30,63,71}$ Furthermore, mood remained stable, and quality of life scores improved in those patients who experienced seizure remission.

Neocortical Foci. There are no published reports on the use of SRS for nonstructural lesion neocortical foci. Régis has presented a small series of cases in which radiosurgery was delivered to perisylvian regions, including the insular cortex, following localization of the seizure focus with stereo-electroencephalography (SEEG) recordings (J. Régis, personal communication, 2012). Because localization of seizure foci in nonlesional neocortical epilepsies usually requires invasive techniques, the noninvasive nature of SRS loses some advantage. One 
may speculate that if noninvasive localization and brain mapping were rigorous enough to supplant invasive methods, then SRS might have a future role.

Corpus Callosotomy. Transection of the corpus callosum may decrease the severity and number of primary generalized or rapidly propagating secondarily generalized seizures in patients who are not otherwise good surgical candidates. In small case series, improvement in seizures following SRS resection of the corpus callosum was comparable to that reported after open callosotomy, with lack of notable complications. ${ }^{16,51}$

\section{Potential Problems Unique to SRS}

Trials of SRS for HH and MTLE highlight one of the potential shortcomings of SRS relative to open surgery, the latency of development of the radiosurgical lesion.

In $\mathrm{HH}$, changes in seizure frequency first occur at earliest 2 months after SRS. Seizures may transiently worsen in frequency before reduction and remission occur. Behavioral improvements, along with EEG normalization, tend to occur in a more linear fashion. ${ }^{60}$

In the case of MTLE, clinical effects-typically headache and transient emergence of auras-begin to emerge around 6 months after SRS, and most clinical or neuroimaging changes occur between 9 and 15 months. The most dramatic drop in seizure rate occurs between 12 and 18 months, ${ }^{2,59}$ coinciding with the development and resolution of maximal MRI changes. ${ }^{9}$ Lower-dose protocols early in the SRS-MTLE experience were reported to be associated with marked seizure worsening and, in 3 cases, deaths associated with probable sudden unexpected death in epilepsy (SUDEP). ${ }^{52,68}$ One death, reported by Prayson and Yoder, occurred 2 weeks postradiation and was due to "persistent seizure complications." Because radiographic changes occur within time intervals on the order of months, rather than days, it is unlikely that radiosurgery contributed to this patient's outcome. An autopsy showing mesial temporal sclerosis but no radiation-induced pathology supports this interpretation..$^{52}$ Additional mortality was reported by Srikijvilaikul et al., who described 1 death at 1 month and another at 1 year following radiosurgery ${ }^{68}$ Both were attributed to complications of seizures, consistent with SUDEP.

A notable "escape hatch" is available for patients who do not respond to SRS. For example, a protocol-defined severe event was reported in the US Multicenter Trial when, at 15 months after SRS, a patient underwent standard ATL for continuing seizures and persistent radiation edema.

Oncogenesis attributable to radiation is another controversial aspect of SRS. Given that most use of SRS is for treatment of tumors, overall life expectancy and the confounder of preexistent tumor make the investigation of this aspect difficult. At the low end, a best estimate from 1 meta-analysis determined that 3 cases with reasonable evidence of oncogenesis occurred in 200,000 uses $(0.0015 \%) .{ }^{24}$ At the high end, of tumors seen in patients treated for AVM (eliminating the primary tumor confounder) in a single center, the cumulative rate of probably SRS-induced tumors in those with a minimum of 10-year follow-up was 3 in 4692 person-years $(0.64 \%){ }^{69}$

\section{Summary}

In summary, seizure remission rates following SRS vary, but the larger, multicenter trials with higher-dose protocols showed remission rates similar to the gold standard of open surgery. Favorable neurocognitive outcomes compared with open surgery suggest that the highly selective radiosurgical lesion may provide some benefit. Note that there are no studies that directly compare open surgery and SRS. However, the ROSE Trial (Radiosurgery or Open Surgery for Epilepsy), a prospective randomized trial of standard open surgery versus SRS, is currently underway. The ROSE Trial may provide further evidence regarding the effects of SRS on neuropsychological functioning and whether cognitive abilities may be less adversely affected by SRS relative to traditional open surgery.

\section{Thermocoagulation Methods}

The next 3 methods share the principle of causing a permanent lesion by heating brain tissue until proteins denature above $45^{\circ} \mathrm{C}^{14}$ They differ in how focal heating is introduced to the target.

\section{Stereotactic Radiofrequency Thermocoagulation}

Stereotactic radiofrequency thermocoagulation is a procedure during which a monopolar needle, under stereotactic guidance, is inserted into the surgical target. Current at high frequency (i.e., radiofrequency above $250 \mathrm{kHz}$ ) is injected, resulting in heating of tissue at the electrode tip. Since recording and stimulation can be performed with the same electrode, recordings from the lesion, electrical stimulation to evoke seizures, and thermocoagulation can all be accomplished efficiently.

There is a long history of the use of SRT to induce focal lesions to interrupt epileptic networks reported in a variety of small case series performed before the mid1990s. For brevity's sake, we quote Neil Kitchen in his review of these studies: "in all instances follow-up has been short and success unpredictable, with not an insignificant risk of complications, and as a result the overall clinical impression of the procedures is that good outcomes are patchy and improvements unsustained." ${ }^{37}$ The experience perhaps is more demonstrative of the limitations of drawing conclusions from idiosyncratic case series and a lack of well-organized prospective trials than from the limitations of the technique itself.

\section{Hypothalamic Hamartomas}

Most recent uses of SRT in the treatment of epilepsy are reported in retrospective case reports and small case series of HH. ${ }^{22,23,32,33,39,72,77}$ Kameyama et al. reported the largest group, consisting of 25 patients, of whom 19 (76\%) had seizure remission. As seen in the SRS group, substantial improvements in behavior also occurred. ${ }^{33}$ Complications in this series included evidence of hypothalamic dysfunction in more than $50 \%$ of patients (poikilothermia, hyperphagia, hyponatremia, and Horner's syndrome, all transient) as well as unexpected subdural hematoma in 2 patients. 


\section{Physiological Lesions}

Selective lesions for MTLE and for neocortical epilepsies have also been performed with SRT., ${ }^{72,49,50}$ In an early series of 25 patients who underwent either unilateral or bilateral amygdalotomies performed for psychiatric surgery, comorbid psychomotor seizures fortuitously decreased or ceased in 9 subjects. Numerous subsequent studies on amygdalotomies or amygdalohippocampectomies have been published, but here we focus on 2 of the larger series. The earlier series, reported by Parrent and Blume, ${ }^{50}$ is notable for its excellent review on SRT. In this study, 22 subjects with MTLE underwent SRT performed using 2 different techniques. In the first group of 5 patients, SRT lesions were confined to the amygdala and the anterior 13-21 $\mathrm{mm}$ of the hippocampus. Only $1 \mathrm{pa}-$ tient (20\%) experienced improvement according to their criteria of remission or limited auras or $>90 \%$ seizure reduction. In the second group of 15 patients, "confluent" SRT lesions of the entire amygdala and anterior midhippocampus, extending up to $34 \mathrm{~mm}$ posteriorly, were performed, resulting in 9 patients $(60 \%)$ with favorable outcome and $2(13 \%)$ completely seizure free. Notably, the target did not include the entorhinal cortex, thought to be a key structure in evaluating the likelihood of seizure freedom following open surgery for MTLE. ${ }^{67}$

The more recent series, reported by Guénot et al., is notable for the recording and creation of radiofrequency lesions with the same set of implanted SEEG depth electrodes. ${ }^{26}$ This study comprised 20 patients with lesionless limbic and cortical epilepsies who had seizure foci localized with the use of SEEG depth electrodes. Radiofrequency lesions were created where focal seizures arose, with the number of coagulations ranging from 2 to 13 . Three patients (15\%) were seizure free short term, with another 8 experiencing $>80 \%$ improvement in seizure frequency. No permanent complications arose. Several patients reported transient symptoms corresponding to lesion location.

The aforementioned studies demonstrate both the strengths and the weaknesses of SRT. On one hand, the small lesions confer little risk to normal brain function, can be performed quickly without large craniotomy, have short recovery times, and in the case of combined recording/coagulation electrodes, require a minimum of operative manipulation. On the other hand, the small size of radiofrequency lesions leaves patients vulnerable to poor outcomes, since the total volume of lesion may not be sufficient to interrupt the epileptic circuit. As experience with open surgery teaches (and as seen in long-term outcomes after $\mathrm{SRS}^{4}$ ), the total volume of resection (in the case of MTLE) correlates with surgical success ${ }^{65}$ because either the epileptic network is unperturbed or regions of the epileptic zone remain outside the boundaries of the minimally invasive lesion.

\section{Laser-Induced Thermal Therapy}

The term "laser" is an acronym for "light amplification by stimulated emission of radiation." Laser-induced thermal therapy, also designated as MRI-guided thermal laser ablation (MTLA), refers to elevation of tissue temperature to a lethal level, producing tissue coagulation via laser delivery. When laser light is introduced into a tissue, the photons introduced into the tissue are either scattered (reflected to adjacent tissue components) or absorbed by the tissue components, or they exit the tissue. The mechanism of thermal therapy is that the photon energy is absorbed and transferred to molecules in the tissue, which leads to direct heating of the tissue. The optical properties of the target tissue determine the extent to which photons will penetrate to adjacent tissue components or absorb near the site of delivery, and both aspects relate to the eventual volume of the thermal ablation lesion. For LITT in human tissue, FDA-approved wavelengths for LITT technology are in the infrared 800- to 1064-nm range, just beyond visible light. For LITT use in epilepsy, the wavelength is generally $980 \mathrm{~nm}^{.74}$

As with real estate, location in LITT matters; nearby tissue components such as blood, water, and melanin mainly absorb photon energy and may serve as a heat sink. Therefore, relatively homogeneous tissue structures, such as the amygdalohippocampal complex, with appropriate photon delivery, will ablate fairly uniformly, with a rapid drop-off of heat ablation as the LITT reaches surrounding cysternal, ventricular, and vascular structures.

LITT requires stereotactic intracranial placement of a laser applicator/guide in the operating room, followed by performance of the actual ablation under MRI guidance. The eventual ablation is confirmed by immediate post-ablation T1-weighted or FLAIR MR images. The transition zone - that is, the volume demarcating affected from unaffected tissue-is quite sharp, about $1 \mathrm{~mm}$ in depth. Therefore, LITT allows a highly selective structural application via a minimally invasive procedure.

Currently, 2 commercial entities provide LITT technology. The Visualase system (http://www.visualaseinc. $\mathrm{com} /$ ) received FDA clearance in August 2007 for a variety of focal surgeries within and outside of the brain. The Monteris Medical system (www.monteris.com/) received FDA clearance in late 2010 (previous approval in Canada), with a product name change in 2012 to the NeuroBlate System for brain surgery.

Peer-reviewed studies on the use of LITT for epilepsy are still few in number. In a recent series of 13 patients with intractable temporal epilepsy treated with LITT, 9 of whom had mesial temporal sclerosis, the mean ablated amygdalohippocampal complex volume was $60 \%$. The only complication was a visual field cut in 1 patient, which was associated with deviation of the applicator insertion and was not from LITT. The median hospital stay was 1 day, and 77\% (10/13) of patients achieved meaningful seizure reduction; 54\% (7/13) were free of disabling seizures during a follow-up period of 5-26 months (median 14 months). ${ }^{80}$

LITT has been reported in the treatment of $\mathrm{HH}$. In a recently reported study of medically refractory gelastic epilepsy due to HH in patients who underwent LITT ablation, 12 (86\%) of the 14 patients achieved seizure freedom, with mean follow-up of 9 months..$^{15}$ The authors reported that no permanent surgical complications, neurological deficits, or neuroendocrine disturbances occurred. The 
median hospital stay was 1 day. Additionally, 2 cases of periventricular nodular heterotopia with epilepsy treated successfully with LITT have been reported. ${ }^{21}$

In summary, the spectrum of appropriate use, expected outcomes, and complications for LITT in epilepsy appears to be evolving. The "immediate feedback" of the LITT lesion revealed by MRI and without a latency period of lesion development (as required in SRS) has appeal, but LITT has yet to be explored in a systematic fashion.

\section{MRI-Guided FUS Ablation}

Focused ultrasound devices (for example, the ExBlate Neuro, Insightec) do exactly what the name suggests: high-energy sound waves of $230-1000 \mathrm{kHz}$, generated by 1024 emitters, are focused through techniques such as the spatial array of emitters, choice of frequency, and the manipulation of phase to direct energy to a central point at which temperature can be raised and lowered to create a transient or permanent lesion. ${ }^{48}$ The location, volume, and change of temperature are monitored in real time with simultaneous MRI. Originally, because the skull diffuses ultrasound signals significantly, "minimally invasive" was a misnomer since craniotomies were required. However, subsequent work has largely overcome some of these challenges, and targets within homogeneous, deep regions of the brain allow reliable focusing without dispersal of signal and without unpredictable "radiator" effects of rapid heat transfer away from the target.

Accordingly, seminal trials of MRI-guided FUS have been conducted in the treatment of glioblastoma ${ }^{45}$ and chronic neuropathic pain via medial thalamotomies, ${ }^{43}$ and in the treatment of essential tremor through lesions of the ventral intermediate nucleus of the thalamus. ${ }^{17}$ Like SRS, FUS appears to be "the maximum of minimums," because it (potentially) requires no craniotomies. Although patients require some sedation to comply with long procedure times, there is no need for general anesthesia, and with growing experience, the need for inpatient postoperative monitoring has decreased. Unlike SRS, results are presented in real time. One could imagine that the truly minimally invasive nature of FUS would allow a series of lesions across time based on interoperative periods of observation to determine the extent of seizure remission. However, technological limitations prohibit its current application to traditional limbic and neocortical epilepsies. Both amygdalohippocampal and neocortical targets currently are too close to the skull; critical heating of the skull and structures outside the target region can result. These limitations are being actively addressed. ${ }^{48}$

\section{Summary}

The search for safe and effective minimally invasive neurosurgical techniques in epilepsy surgery has a long and largely successful history. The limitations of these techniques lie mainly within the limitations of the uncertain physiology of epilepsy rather than in the techniques themselves. Basic localization of the epileptic zone remains a critical challenge because, as demonstrated in several of the trials noted above, the very feature of mini- mally invasive techniques that attracts us to their usethe superselectivity of the lesions caused by SRS, SRT, LITT, and FUS - often work against seizure remission since many patients have epileptic zones that defy definitive mapping or exceed volumes that can reasonably be called "minimally invasive." However, many epileptologists may be too familiar with the limitations of open surgery. Often we feel that patients have "one good surgery" in them, and we find them reluctant to return to repeat open surgeries in the case of poor efficacy. What these techniques offer in common, especially LITT and FUS, is the ability to perform serial ablations in a segmented approach. In this paradigm, a minimally invasive technique is called upon to ablate the best-defined target, and the patient is observed for a period of time. If remission does not occur, then repeat ablation can be performed, perhaps following some additional localization.

As epileptologists who conduct epilepsy drug trials in addition to being involved in epilepsy surgery evaluations, we note that almost all of these studies have been conducted in a manner endemic in neurosurgical clinical research; single-center, retrospective case reports and small case series predominate. True comparisons among studies and even within reports are difficult since patient recruitment does not follow clear inclusion and exclusion criteria and methods are serially "tweaked" to accommodate patient inhomogeneity. Outcomes are usually cross-sectional rather than followed in a uniform time base. Primary outcomes-seizure remission-are judged in a variety of ways across studies, and secondary outcomes-patient disability, quality of life, cognition, and mood-are either ignored or qualitatively described rather than measured in accepted neurocognitive scales. To date, only 4 randomized, controlled trials of epilepsy surgery have been published, ${ }^{18,79,81}$ one of them the US Multicenter Study of SRS discussed above. A handful of publicly funded, prospective observational studies exist. Two publicly funded trials, the ERSET (Early Randomized Surgical Epilepsy Trial) study of the benefits of early $\mathrm{ATL}^{18}$ and the ongoing ROSE Trial evaluating open surgery versus SRS, were closed early because of insufficient recruitment. Although recent and ongoing studies of LITT and FUS have many of the features of a modern, well-conducted clinical trial, none achieve Class 1 evidence levels.

In short, it is difficult to conduct robust, unbiased trials in the field of epilepsy surgery. We challenge the researchers of future studies of minimally invasive techniques to design trials with unbiased judging, robust design, and common, validated outcome measures.

\section{Disclosure}

Dr. Quigg reports funding from NIH-NINDS U01 NS $058634-$ 01A2 and NIH-NIMH R01MH086758. Dr. Harden reports funding or fees from NIH-NINDS, UCB, Upsher-Smith, and Wiley.

Author contributions to the study and manuscript preparation include the following. Conception and design: Quigg. Acquisition of data: both authors. Analysis and interpretation of data: Quigg. Drafting the article: both authors. Critically revising the article: Quigg. Reviewed submitted version of manuscript: both authors. Approved the final version of the manuscript on behalf of both authors: Quigg. 
Administrative/technical/material support: Quigg. Study supervision: Quigg.

\section{References}

1. Barajas MA, Ramírez-Guzman MG, Rodríguez-Vázquez C, Toledo-Buenrostro V, Cuevas-Solórzano A, Rodríguez-Hernández G: Gamma knife surgery for hypothalamic hamartomas accompanied by medically intractable epilepsy and precocious puberty: experience in Mexico. J Neurosurg 102 Suppl:53-55, 2005

2. Barbaro NM, Quigg M, Broshek DK, Ward MM, Lamborn KR, Laxer KD, et al: A multicenter, prospective pilot study of gamma knife radiosurgery for mesial temporal lobe epilepsy: seizure response, adverse events, and verbal memory. Ann Neurol 65:167-175, 2009

3. Bartolomei F, Hayashi M, Tamura M, Rey M, Fischer C, Chauvel $\mathrm{P}$, et al: Long-term efficacy of gamma knife radiosurgery in mesial temporal lobe epilepsy. Neurology 70:16581663,2008

4. Bartolomei F, Régis J, Kida Y, Kobayashi T, Vladyka V, Liscàk R, et al: Gamma Knife radiosurgery for epilepsy associated with cavernous hemangiomas: a retrospective study of 49 cases. Stereotact Funct Neurosurg 72 (Suppl 1):22-28, 1999

5. Baumann CR, Schuknecht B, Lo Russo G, Cossu M, Citterio A, Andermann F, et al: Seizure outcome after resection of cavernous malformations is better when surrounding hemosiderin-stained brain also is removed. Epilepsia 47:563-566, 2006

6. Benbadis SR, Heriaud L, Tatum WO, Vale FL: Epilepsy surgery, delays and referral patterns-are all your epilepsy patients controlled? Seizure 12:167-170, 2003

7. Blume WT, Parrent AG, Kaibara M: Stereotactic amygdalohippocampotomy and mesial temporal spikes. Epilepsia 38: 930-936, 1997

8. Cappabianca P, Alfieri A, Maiuri F, Mariniello G, Cirillo S, de Divitiis E: Supratentorial cavernous malformations and epilepsy: seizure outcome after lesionectomy on a series of 35 patients. Clin Neurol Neurosurg 99:179-183, 1997

9. Chang EF, Quigg M, Oh MC, Dillon WP, Ward MM, Laxer KD, et al: Predictors of efficacy after stereotactic radiosurgery for medial temporal lobe epilepsy. Neurology 74:165172,2010

10. Chelune GJ, Najm IM: Risk factors associated with postsurgical decrements in memory decline after anterior temporal lobectomy, in Luders HO, Comair Y (eds): Epilepsy Surgery, ed 2. Philadelphia: Lippincott Williams \& Wilkins, 2000, pp 497-504

11. Chen ZF, Kamiryo T, Henson SL, Yamamoto H, Bertram EH, Schottler F, et al: Anticonvulsant effects of gamma surgery in a model of chronic spontaneous limbic epilepsy in rats. J Neurosurg 94:270-280, 2001

12. Cmelak AJ, Abou-Khalil B, Konrad PE, Duggan D, Maciunas RJ: Low-dose stereotactic radiosurgery is inadequate for medically intractable mesial temporal lobe epilepsy: a case report. Seizure 10:442-446, 2001

13. Cohen DS, Zubay GP, Goodman RR: Seizure outcome after lesionectomy for cavernous malformations. J Neurosurg 83: 237-242, 1995

14. Cosman ER, Cosman BJ: Radiofrequency lesion-making in the nervous system, in Wilkins RH, Rengachary SS (eds): Neurosurgery, ed 2. New York: McGraw-Hill, 1996, pp 4119-4138

15. Curry DJ, Gowda A, McNichols RJ, Wilfong AA: MR-guided stereotactic laser ablation of epileptogenic foci in children. Epilepsy Behav 24:408-414, 2012

16. Eder HG, Feichtinger M, Pieper T, Kurschel S, Schroettner O: Gamma knife radiosurgery for callosotomy in children with drug-resistant epilepsy. Childs Nerv Syst 22:1012-1017, 2006
17. Elias WJ, Huss D, Voss T, Loomba J, Khaled M, Zadicario E, et al: A pilot study of focused ultrasound thalamotomy for essential tremor. N Engl J Med 369:640-648, 2013

18. Engel J Jr, McDermott MP, Wiebe S, Langfitt JT, Stern JM, Dewar S, et al: Early surgical therapy for drug-resistant temporal lobe epilepsy: a randomized trial. JAMA 307:922-930, 2012

19. Engel J Jr, Wiebe S, French J, Sperling M, Williamson P, Spencer D, et al: Practice parameter: temporal lobe and localized neocortical resections for epilepsy: report of the Quality Standards Subcommittee of the American Academy of Neurology, in association with the American Epilepsy Society and the American Association of Neurological Surgeons. Neurology 60:538-547, 2003

20. Englot DJ, Ouyang D, Garcia PA, Barbaro NM, Chang EF: Epilepsy surgery trends in the United States, 1990-2008. Neurology 78:1200-1206, 2012

21. Esquenazi Y, Kalamangalam GP, Slater JD, Knowlton RC, Friedman E, Morris SA, et al: Stereotactic laser ablation of epileptogenic periventricular nodular heterotopia. Epilepsy Res 108:547-554, 2014

22. Fujimoto Y, Kato A, Saitoh Y, Ninomiya H, Imai K, Hashimoto $\mathrm{N}$, et al: Open radiofrequency ablation for the management of intractable epilepsy associated with sessile hypothalamic hamartoma. Minim Invasive Neurosurg 48:132-135, 2005

23. Fujimoto Y, Kato A, Saitoh Y, Ninomiya H, Imai K, Sakakibara RI, et al: Stereotactic radiofrequency ablation for sessile hypothalamic hamartoma with an image fusion technique. Acta Neurochir (Wien) 145:697-701, 2003

24. Ganz JC: Gamma knife radiosurgery and its possible relationship to malignancy: a review. J Neurosurg 97 (5 Suppl): 644-652, 2002

25. Gerszten PC, Adelson PD, Kondziolka D, Flickinger JC, Lunsford LD: Seizure outcome in children treated for arteriovenous malformations using gamma knife radiosurgery. Pediatr Neurosurg 24:139-144, 1996

26. Guénot $M$, Isnard J, Ryvlin $P$, Fischer $C$, Mauguière F, Sindou M: SEEG-guided RF thermocoagulation of epileptic foci: feasibility, safety, and preliminary results. Epilepsia 45:13681374, 2004

27. Heikkinen ER, Konnov B, Melnikov L, Yalynych N, Zubkov Yu N, Garmashov Yu A, et al: Relief of epilepsy by radiosurgery of cerebral arteriovenous malformations. Stereotact Funct Neurosurg 53:157-166, 1989

28. Hensley-Judge H, Quigg M, Barbaro NM, Newman SA, Ward MM, Chang EF, et al: Visual field defects after radiosurgery for mesial temporal lobe epilepsy. Epilepsia 54:1376-1380, 2013

29. Hermann BP, Seidenberg M, Dohan FC Jr, Wyler AR, Haltiner A, Bobholz J, et al: Reports by patients and their families of memory change after left anterior temporal lobectomy: relationship to degree of hippocampal sclerosis. Neurosurgery 36:39-45, 1995

30. Hermann BP, Wyler AR, Bush AJ, Tabatabai FR: Differential effects of left and right anterior temporal lobectomy on verbal learning and memory performance. Epilepsia 33:289-297, 1992

31. Hoggard N, Wilkinson ID, Griffiths PD, Vaughan P, Kemeny AA, Rowe JG: The clinical course after stereotactic radiosurgical amygdalohippocampectomy with neuroradiological correlates. Neurosurgery 62:336-346, 2008

32. Homma J, Kameyama S, Masuda H, Ueno T, Fujimoto A, Oishi M, et al: Stereotactic radiofrequency thermocoagulation for hypothalamic hamartoma with intractable gelastic seizures. Epilepsy Res 76:15-21, 2007

33. Kameyama S, Murakami H, Masuda H, Sugiyama I: Minimally invasive magnetic resonance imaging-guided stereotactic radiofrequency thermocoagulation for epileptogenic hypothalamic hamartomas. Neurosurgery 65:438-449, 2009 
34. Karlsson B, Kihlström L, Lindquist C, Ericson K, Steiner L: Radiosurgery for cavernous malformations. J Neurosurg 88:293-297, 1998

35. Kawai K, Suzuki I, Kurita H, Shin M, Arai N, Kirino T: Failure of low-dose radiosurgery to control temporal lobe epilepsy. Report of two cases. J Neurosurg 95:883-887, 2001

36. Kim MS, Pyo SY, Jeong YG, Lee SI, Jung YT, Sim JH: Gamma knife surgery for intracranial cavernous hemangioma. J Neurosurg 102 Suppl:102-106, 2005

37. Kitchen N: Experimental and clinical studies on the putative therapeutic efficacy of cerebral irradiation (radiotherapy) in epilepsy. Epilepsy Res 20:1-10, 1995

38. Kurita H, Kawamoto S, Suzuki I, Sasaki T, Tago M, Terahara A, et al: Control of epilepsy associated with cerebral arteriovenous malformations after radiosurgery. J Neurol Neurosurg Psychiatry 65:648-655, 1998

39. Kuzniecky R, Guthrie B, Mountz J, Bebin M, Faught E, Gilliam F, et al: Intrinsic epileptogenesis of hypothalamic hamartomas in gelastic epilepsy. Ann Neurol 42:60-67, 1997

40. Lhatoo SD, Solomon JK, McEvoy AW, Kitchen ND, Shorvon SD, Sander JW: A prospective study of the requirement for and the provision of epilepsy surgery in the United Kingdom. Epilepsia 44:673-676, 2003

41. Maesawa S, Kondziolka D, Dixon CE, Balzer J, Fellows W, Lunsford LD: Subnecrotic stereotactic radiosurgery controlling epilepsy produced by kainic acid injection in rats. J Neurosurg 93:1033-1040, 2000

42. Malikova H, Vojtech Z, Liscak R, Prochazka T, Vymazal J, Vladyka $\mathrm{V}$, et al: Stereotactic radiofrequency amygdalohippocampectomy for the treatment of mesial temporal lobe epilepsy: correlation of MRI with clinical seizure outcome. Epilepsy Res 83:235-242, 2009

43. Martin E, Jeanmonod D, Morel A, Zadicario E, Werner B: High-intensity focused ultrasound for noninvasive functional neurosurgery. Ann Neurol 66:858-861, 2009

44. Mathieu D, Kondziolka D, Niranjan A, Flickinger J, Lunsford LD: Gamma knife radiosurgery for refractory epilepsy caused by hypothalamic hamartomas. Stereotact Funct Neurosurg 84:82-87, 2006

45. McDannold N, Clement GT, Black P, Jolesz F, Hynynen K: Transcranial magnetic resonance imaging- guided focused ultrasound surgery of brain tumors: initial findings in 3 patients. Neurosurgery 66:323-332, 2010

46. McDonald CR, Norman MA, Tecoma E, Alksne J, Iragui V: Neuropsychological change following gamma knife surgery in patients with left temporal lobe epilepsy: a review of three cases. Epilepsy Behav 5:949-957, 2004

47. Meador KJ: Cognitive outcomes and predictive factors in epilepsy. Neurology 58 (8 Suppl 5):S21-S26, 2002

48. Monteith S, Sheehan J, Medel R, Wintermark M, Eames M, Snell J, et al: Potential intracranial applications of magnetic resonance-guided focused ultrasound surgery. A review. J Neurosurg 118:215-221, 2013

49. Narabayashi H, Mizutani T: Epileptic seizures and the stereotaxic amygdalotomy. Confin Neurol 32:289-297, 1970

50. Parrent AG, Blume WT: Stereotactic amygdalohippocampotomy for the treatment of medial temporal lobe epilepsy. Epilepsia 40:1408-1416, 1999

51. Pendl G, Eder HG, Schroettner O, Leber KA: Corpus callosotomy with radiosurgery. Neurosurgery 45:303-308, 1999

52. Prayson RA, Yoder BJ: Clinicopathologic findings in mesial temporal sclerosis treated with gamma knife radiotherapy. Ann Diagn Pathol 11:22-26, 2007

53. Przybylowski CJ, Ding D, Starcke RM, Yen CP, Quigg M, Dodson B, et al: Seizure and anticonvulsant outcomes following stereotactic radiosurgery for intracranial arteriovenous malformations. J Neurosurg (in press)

54. Quigg M, Broshek DK, Barbaro NM, Ward MM, Laxer KD, Yan G, et al: Neuropsychological outcomes after Gamma
Knife radiosurgery for mesial temporal lobe epilepsy: a prospective multicenter study. Epilepsia 52:909-916, 2011

55. Quigg M, Rolston J, Barbaro NM: Radiosurgery for epilepsy: clinical experience and potential antiepileptic mechanisms. Epilepsia 53:7-15, 2012

56. Régis J, Bartolomei F, de Toffol B, Genton P, Kobayashi T, Mori Y, et al: Gamma knife surgery for epilepsy related to hypothalamic hamartomas. Neurosurgery 47:1343-1352, 2000

57. Régis J, Bartolomei F, Rey M, Genton P, Dravet C, Semah F, et al: Gamma knife surgery for mesial temporal lobe epilepsy. Epilepsia 40:1551-1556, 1999

58. Régis J, Peragui JC, Rey M, Samson Y, Levrier O, Porcheron D, et al: First selective amygdalohippocampal radiosurgery for 'mesial temporal lobe epilepsy.' Stereotact Funct Neurosurg 64 (Suppl 1):193-201, 1995

59. Régis J, Rey M, Bartolomei F, Vladyka V, Liscak R, Schröttner $\mathrm{O}$, et al: Gamma knife surgery in mesial temporal lobe epilepsy: a prospective multicenter study. Epilepsia 45:504-515, 2004

60. Régis J, Scavarda D, Tamura M, Nagayi M, Villeneuve N, Bartolomei F, et al: Epilepsy related to hypothalamic hamartomas: surgical management with special reference to gamma knife surgery. Childs Nerv Syst 22:881-895, 2006

61. Schäuble B, Cascino GD, Pollock BE, Gorman DA, Weigand S, Cohen-Gadol AA, et al: Seizure outcomes after stereotactic radiosurgery for cerebral arteriovenous malformations. Neurology 63:683-687, 2004

62. Schröttner O, Eder HG, Unger F, Feichtinger K, Pendl G: Radiosurgery in lesional epilepsy: brain tumors. Stereotact Funct Neurosurg 70 (Suppl 1):50-56, 1998

63. Seidenberg M, Hermann B, Wyler AR, Davies K, Dohan FC Jr, Leveroni C: Neuropsychological outcome following anterior temporal lobectomy in patients with and without the syndrome of mesial temporal lobe epilepsy. Neuropsychology 12:303-316, 1998

64. Selch MT, Gorgulho A, Mattozo C, Solberg TD, CabatanAwang C, DeSalles AA: Linear accelerator stereotactic radiosurgery for the treatment of gelastic seizures due to hypothalamic hamartoma. Minim Invasive Neurosurg 48:310-314, 2005

65. Shamim S, Wiggs E, Heiss J, Sato S, Liew C, Solomon J, et al: Temporal lobectomy: resection volume, neuropsychological effects, and seizure outcome. Epilepsy Behav 16:311-314, 2009

66. Shih YH, Pan DH: Management of supratentorial cavernous malformations: craniotomy versus gammaknife radiosurgery. Clin Neurol Neurosurg 107:108-112, 2005

67. Siegel AM, Wieser HG, Wichmann W, Yaşargil GM: Relationships between MR-imaged total amount of tissue removed, resection scores of specific mediobasal limbic subcompartments and clinical outcome following selective amygdalohippocampectomy. Epilepsy Res 6:56-65, 1990

68. Srikijvilaikul T, Najm I, Foldvary-Schaefer N, Lineweaver T, Suh JH, Bingaman WE: Failure of gamma knife radiosurgery for mesial temporal lobe epilepsy: report of five cases. Neurosurgery 54:1395-1404, 2004

69. Starke RM, Yen CP, Chen CJ, Ding D, Mohila CA, Jensen ME, et al: An updated assessment of the risk of radiation-induced neoplasia after radiosurgery of arteriovenous malformations. World Neurosurg [epub ahead of print], 2013

70. Steiner L, Lindquist C, Adler JR, Torner JC, Alves W, Steiner M: Clinical outcome of radiosurgery for cerebral arteriovenous malformations. J Neurosurg 77:1-8, 1992

71. Stroup E, Langfitt J, Berg M, McDermott M, Pilcher W, Como P: Predicting verbal memory decline following anterior temporal lobectomy (ATL). Neurology 60:1266-1273, 2003

72. Taniguchi H, Muragaki Y, Iseki H, Nakamura R, Taira T: New radiofrequency coil integrated with a stereotactic frame for 
intraoperative MRI-controlled stereotactically guided brain surgery. Stereotact Funct Neurosurg 84:136-141, 2006

73. Thom M, Mathern GW, Cross JH, Bertram EH: Mesial temporal lobe epilepsy: how do we improve surgical outcome? Ann Neurol 68:424-434, 2010

74. Tovar-Spinoza Z, Carter D, Ferrone D, Eksioglu Y, Huckins S: The use of MRI-guided laser-induced thermal ablation for epilepsy. Childs Nerv Syst 29:2089-2094, 2013

75. Unger F, Schröttner O, Feichtinger M, Bone G, Haselsberger K, Sutter B: Stereotactic radiosurgery for hypothalamic hamartomas. Acta Neurochir Suppl 84:57-63, 2002

76. Vojtěch Z, Vladyka V, Kalina M, Nespor E, Seltenreichová K, Semnická J, et al: The use of radiosurgery for the treatment of mesial temporal lobe epilepsy and long-term results. Epilepsia 50:2061-2071, 2009

77. Wang W, Wang W, Guo X, Zeng Y, Jiang X: Hypothalamic hamartoma causing gelastic seizures treated with stereotactic radiofrequency thermocoagulation. Epileptic Disord 11:333338, 2009

78. Wellis G, Nagel R, Vollmar C, Steiger HJ: Direct costs of microsurgical management of radiosurgically amenable intracranial pathology in Germany: an analysis of meningiomas, acoustic neuromas, metastases and arteriovenous malformations of less than $3 \mathrm{~cm}$ in diameter. Acta Neurochir (Wien) 145:249-255, 2003
79. Wiebe S, Blume WT, Girvin JP, Eliasziw M: A randomized, controlled trial of surgery for temporal-lobe epilepsy. N Engl J Med 345:311-318, 2001

80. Willie JT, Laxpati NG, Drane DL, Gowda A, Appin C, Hao C, et al: Real-time magnetic resonance-guided stereotactic laser amygdalohippocampotomy for mesial temporal lobe epilepsy. Neurosurgery 74:569-585, 2014

81. Wyler AR, Hermann BP, Somes G: Extent of medial temporal resection on outcome from anterior temporal lobectomy: a randomized prospective study. Neurosurgery 37:982-991, 1995

Manuscript submitted July 8, 2014

Accepted August 8, 2014.

Portions of this article were presented at the 17th International Leksell Gamma Knife Society Meeting, New York, New York, May $11-15,2014$

Please include this information when citing this paper: DOI: 10.3171/2014.8.GKS141608.

Address correspondence to: Mark Quigg, M.D., M.Sc., Department of Neurology, Box 800394, University of Virginia, Charlottesville, VA 22902. email: quigg@virginia.edu. 